\title{
Near-term Horizontal Launch for Flexible Operations: Results of the DARPA/NASA Horizontal Launch Study
}

\author{
Paul A. Bartolotta ${ }^{1}$ \\ NASA Glenn Research Center, Cleveland, Ohio, 44135 \\ Alan W. Wilhite ${ }^{2}$ \\ Georgia Institute of Technology, Hampton, Virginia, 23681 \\ Mark G. Schaffer ${ }^{3}$ \\ SpaceWorks Enterprises, Inc., Atlanta, GA, 30338 \\ Lawrence D. Huebner ${ }^{4}$ \\ NASA Langley Research Center, Hampton, Virginia, 23681 \\ Randall T. Voland ${ }^{5}$ \\ ACEnT Laboratories LCC, Hampton, Virginia, 23669 \\ and \\ David F. Voracek ${ }^{6}$ \\ NASA Dryden Flight Research Center, Edwards, California, 93523
}

\begin{abstract}
Horizontal launch has been investigated for 60 years by over 130 different studies. During this time only one concept, Pegasus, has ever been in operation. The attractiveness of horizontal launch is the capability to provide a "mobile launch pad" that can use existing aircraft runways, cruise above weather, loiter for mission instructions, and provide precise placement for orbital intercept, rendezvous, or reconnaissance.

A jointly sponsored study by DARPA and NASA, completed in 2011, explored the trade space of horizontal launch system concepts which included an exhaustive literature review of the past 70 years. The Horizontal Launch Study identified potential near- and mid-term concepts capable of delivering $15,000 \mathrm{lb}$ payloads to a $28.5^{\circ}$ due East inclination, 100 nautical-mile low-Earth orbit. Results are presented for a range of near-term system concepts selected for their availability and relatively low design, development, test, and evaluation (DDT\&E) costs. This study identified a viable low-cost development path forward to make a robust and resilient horizontal launch capability a reality.
\end{abstract}

\section{Nomenclature}

ACES $=$ air collection and enrichment system

DARPA $=$ Defense Advanced Research Projects Agency

DDT\&E = design, development, test, and evaluation

$\mathrm{DRM}=$ design reference mission

\footnotetext{
${ }^{1}$ Senior Aerospace Engineer, Structural Dynamics Branch, 21000 Brookpark Rd. Cleveland OH, 44135 MS 49-8, Senior Member.

${ }^{2}$ Professor, School of Aerospace Engineering, 270 Ferst Drive, NW Atlanta, GA 30332-0150, AIAA Associate Fellow.

${ }^{3}$ Senior Aerospace Engineer, Engineering Division, 1040 Crown Pointe Pkwy. Ste. 950, Senior Member.

${ }^{4}$ Technical Assistant, Space Technology Projects Office, Mail Stop 494, AIAA Associate Fellow.

${ }^{5}$ Vice President, ACENT Laboratories LLC 33 E Sunset Rd Hampton, VA 23669, AIAA Associate Fellow.

${ }^{6}$ NASA Dryden Chief Technologist, Research \& Engineering Directorate, MS 2011 PO Box 273, Edwards CA, AIAA Senior Member.
} 


$\begin{array}{ll}\text { FOM } & =\text { figure of merit } \\ \text { FT } & =\text { flight test system concept } \\ \text { HLS } & =\text { Horizontal Launch Study } \\ \text { IOC } & =\text { initial operational capability } \\ \text { LACE } & =\text { liquid air cycle engine } \\ \text { LCC } & =\text { life cycle cost } \\ \text { LH2 } & =\text { liquid hydrogen } \\ \text { NAFCOM } & \text { NASA/Air Force cost model } \\ \text { PD } & =\text { point design system concept } \\ \text { RBCC } & =\text { rocket-based combined cycle } \\ \text { RP } & =\text { rocket propellant }(\text { RP-1), kerosene } \\ \text { RTA } & =\text { Mach 4+ turbine accelerator engine } \\ \text { TBCC } & =\text { turbine-based combined cycle }\end{array}$

\section{Introduction}

$\mathrm{T}$ HE promise of horizontal take-off space launch systems has inspired many studies over the past 60 yearsspanning airbreathing and rocket propulsion, expendable and reusable launch vehicles, and various assisted launch concepts, such as ground sleds or rail-launch with magnetic levitation. These various studies proved difficult to compare, as each used its own, sometimes unique, ground rules, assumptions, and figures of merit. Most studies focused on narrow mission requirements, such as a single payload class, market, maximum gross take-off weight, or staging Mach number. Only a few included the process for and costs of design, development, testing, production, ground operations, and mission operations. ${ }^{1}$

The primary advantages of horizontal launch is the capability to provide a "mobile launch pad" that can use existing aircraft runways, cruise above weather, loiter for mission instructions, and achieve precise placement for orbital intercept, rendezvous, or reconnaissance. Another compelling benefit of horizontal launch is that today's ground-based vertical launch pads are a single earthquake, hurricane, or terrorist attack away from disruption of critical U.S. launch capabilities.

The study did not attempt to design a new system concept for horizontal launch, but rather focused on the refinement of many previously-studied horizontal launch concepts. Data was collated from 136 published and unpublished unclassified sources in order to assess each design against the figures of merit selected for this study. A variety of factors were considered across these existing studies, from the concepts of operations to technologies and system integration schemes. Because of the large number of past horizontal launch studies, a process was developed to narrow the number of concepts through prescreening, screening, and evaluation of point designs. The refinement process was not intended to select the "best" concept, but rather to establish the feasibility of horizontal launch from a balanced assessment of figures of merit and to identify potential concepts that warrant further exploration.

Examples of the variables that were collected began with size, weight, and payload capability and extended to takeoff options, such as intact, sled assist, sled cross feed, or towed. The staging options included the number of stages, staging speeds, and whether or not a drop tank was used. Integration options included internally contained launch vehicles, embedded launch vehicles, or various attachment methods, such as inline, top, or bottom mounting. Additional data collected included reusability approaches and whether stages were expendable, fully reusable, or partially reusable. Propulsion options included solid rocket motors, liquid rocket motors, airbreathing engines, or integrated combinations. Two options for aerial fueling were subsonic tanker assist and air collection and enrichment (ACES). This depth and breadth of the body of knowledge served to reinforce the validity of the study's approach.

\section{Study Approach}

The study approach progressively narrowed the range of potential concepts considered, reserving higher-fidelity engineering analysis for a subset of the most promising concepts. This narrowing process is shown in Figure 1. The first step was to determine an appropriate set of figures of merit (FOMs) in four categories: safety and mission success, effectiveness and performance, programmatic factors, and affordability, as shown in Table 1. The two discriminating factors identified were pounds of payload delivered to orbit and cost per pound of the delivered payload. Common requirements were also established, including projected annual launch rates and gross take off weight runway limits. 


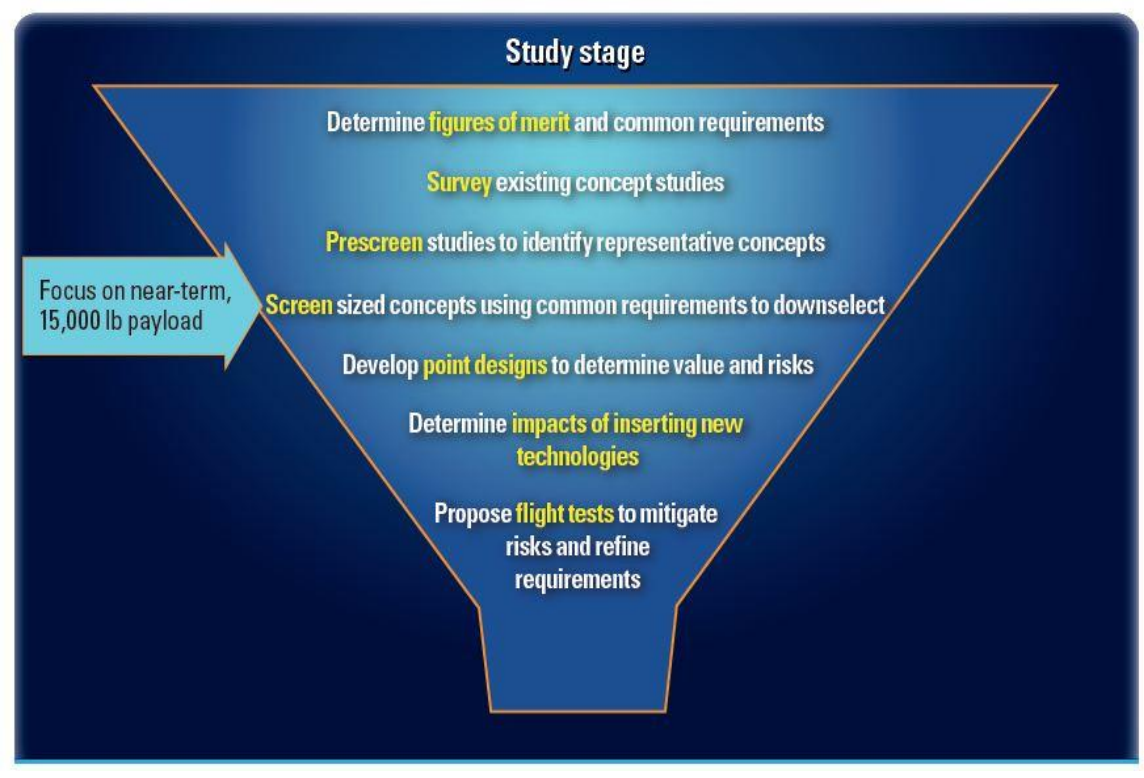

Figure 1. Study approach showing narrowing focus as analysis progressed.
Once the FOMs were established, a literature survey of unclassified horizontal launch concepts from the broad range of designs, studies, and demonstrations that have been developed over the past six decades was conducted. A database of concepts was developed from the published literature and unpublished NASA and DoD horizontal launch studies. These were analyzed to identify 18 representative concepts. These 18 concepts were put through a prescreening process using analysis of alternatives and weighted figures of merit. The concepts were compared to present launch capabilities and projected payload markets to further narrow the field to four concepts that fit the study's common requirements.

Table 1 Figures of Merit used in this Horizontal Launch Study

\begin{tabular}{|c|c|c|c|}
\hline $\begin{array}{l}\text { Safety and Mission } \\
\text { Success }\end{array}$ & $\begin{array}{l}\text { Effectiveness and } \\
\text { Performance }\end{array}$ & $\begin{array}{l}\text { Programmatic } \\
\text { Factors }\end{array}$ & Affordability \\
\hline $\begin{array}{l}\text { - Loss of vehicle } \\
\text { probability, by stage } \\
\text { - Loss of mission } \\
\text { probability }\end{array}$ & $\begin{array}{l}\text { - Payload } \\
\text { - Minimum turnaround } \\
\text { time } \\
\text { - Surge call-up time } \\
\text { - Basing flexibility } \\
\text { - Mission flexibility } \\
\text { - Military viability }\end{array}$ & $\begin{array}{l}\text { - Failure to achieve } \\
\text { DDT\&E goals } \\
\text { - Failure to achieve IOC } \\
\text { date } \\
\text { - Technology maturity } \\
\text { - Commercial viability }\end{array}$ & $\begin{array}{l}\text { - Cost of DDT\&E } \\
\text { - Cost of facilities } \\
\text { - Cost of acquisition and } \\
\text { production } \\
\text { - Cost of operations } \\
\text { - Cost of mission failure }\end{array}$ \\
\hline
\end{tabular}

Factors quantitatively calculated

Factors qualitatively determined using expert elicitation

These four concepts were next expanded in a morphological matrix to thousands of possible configurations, with varying numbers of stages, engines, propulsion systems, propellants, and other features. These configurations were screened in an integrated, parametric engineering environment to level the concepts to the same level of analysis fidelity in order to compute performance metrics and figures of merit. From these results, the team selected three distinct configurations for higher fidelity analysis. These were intended to establish the feasibility of a generic mission that would be useful for both commercial and government launch customers.

Three point designs were generated using higher fidelity engineering methods than were used for screening. The point design results were used to identify DDT\&E feasibility and risk factors. Performance was computed using analysis tools with mid-level fidelity. FOMs were computed for minimum turn-around time, workforce, and cost of operations; dynamic fault trees were used to calculate the probabilities of loss of vehicle and loss of mission; and the NASA/Air Force cost model (NAFCOM) was used to determine DDT\&E and production costs. Finally, the study identified two flight test system concepts focused on very near-term and low-cost subsystems with the goal of demonstrating the system performance and mitigating the highest risk factors of the point designs. 


\section{A. Analyzing Economic Feasibility}

A simple economic feasibility analysis was conducted to better understand the viability of competing systems. This analysis began by extracting cost data from a wide range of past and present launch systems. Nonrecurring costs included ground facilities costs and DDT\&E costs, including purchase and modifications to the carrier aircraft. This assessment did not include technology maturation costs estimated to bring any subsystems or components to a technology readiness level of 6 . Thus, all specified components were assumed to have achieved a system or subsystem model or prototyping demonstration in a relevant end-to-end environment, either on the ground or in flight. Recurring costs included production and acquisition of expendable elements. It also included operations costs such as fuel and ground crew, and the cost of doing business - overhead, general and administrative costs, and profit. Nonrecurring and recurring costs were added to determine the life cycle cost (LCC), which was then amortized over the number of flights or over the pounds of payload delivered to orbit.

Figure 2 shows a spectrum of the price per pound of payload for U.S. launch vehicles. The curve reflects the overall trend in industry pricing, but, of course, does not necessarily scale directly to cost. The highest price per pound of payload on this graph is attributed to Pegasus, the only currently available horizontal launch system. Pegasus is a bottom-mounted launch vehicle with a two-stage solid rocket released from a modified L-1011 aircraft. It can deliver $950 \mathrm{lb}$ of payload to orbit at a price of over $\$ 30,000$ per pound.

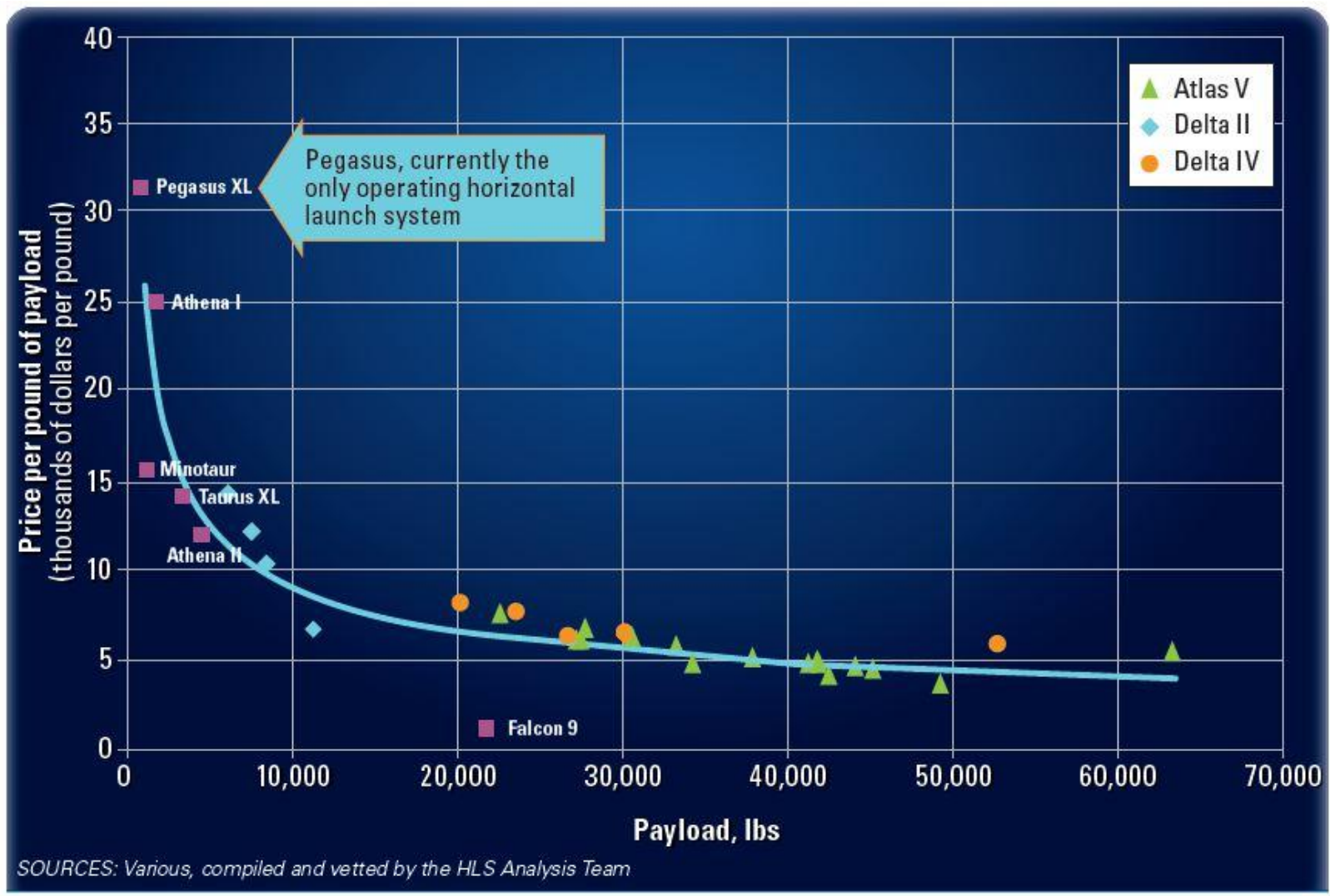

Figure 2. Payload price per pound for existing U.S. launch systems.

DDT\&E cost trends were analyzed. As seen in Figure 3, DDT\&E tends to increase with the inert weight of a system. The box at the top, right hand corner of Figure 3 represents the required inert weight range $-100,000 \mathrm{lb}$ or more - of a carrier aircraft needed to deliver $15,000 \mathrm{lb}$ to orbit. As observed in the study survey, variations in cost for a given inert weight could be attributed to system complexity, system maturity, customer requirements, or testing requirements.

Figure 3 plots a mix of concept aircraft, such as the XB series, and more fully-detailed aircraft intended for commercial production. Average DDT\&E costs for a new Earth-to-orbit technology demonstrator aircraft were 
estimated to be $\$ 10$ billion (in 2010 dollars) for a new subsonic carrier aircraft, and as high as $\$ 17$ billion for a new supersonic and $\$ 25$ billion for a new hypersonic carrier aircraft.

When amortized, these DDT\&E costs can add $\$ 6,000$ to $\$ 13,000$ to each pound of payload to orbit and can easily overwhelm operations costs unless extremely optimistic flight rates are assumed. This analysis found that a new aircraft developed solely for a new horizontal launch system presented a substantial risk to commercial

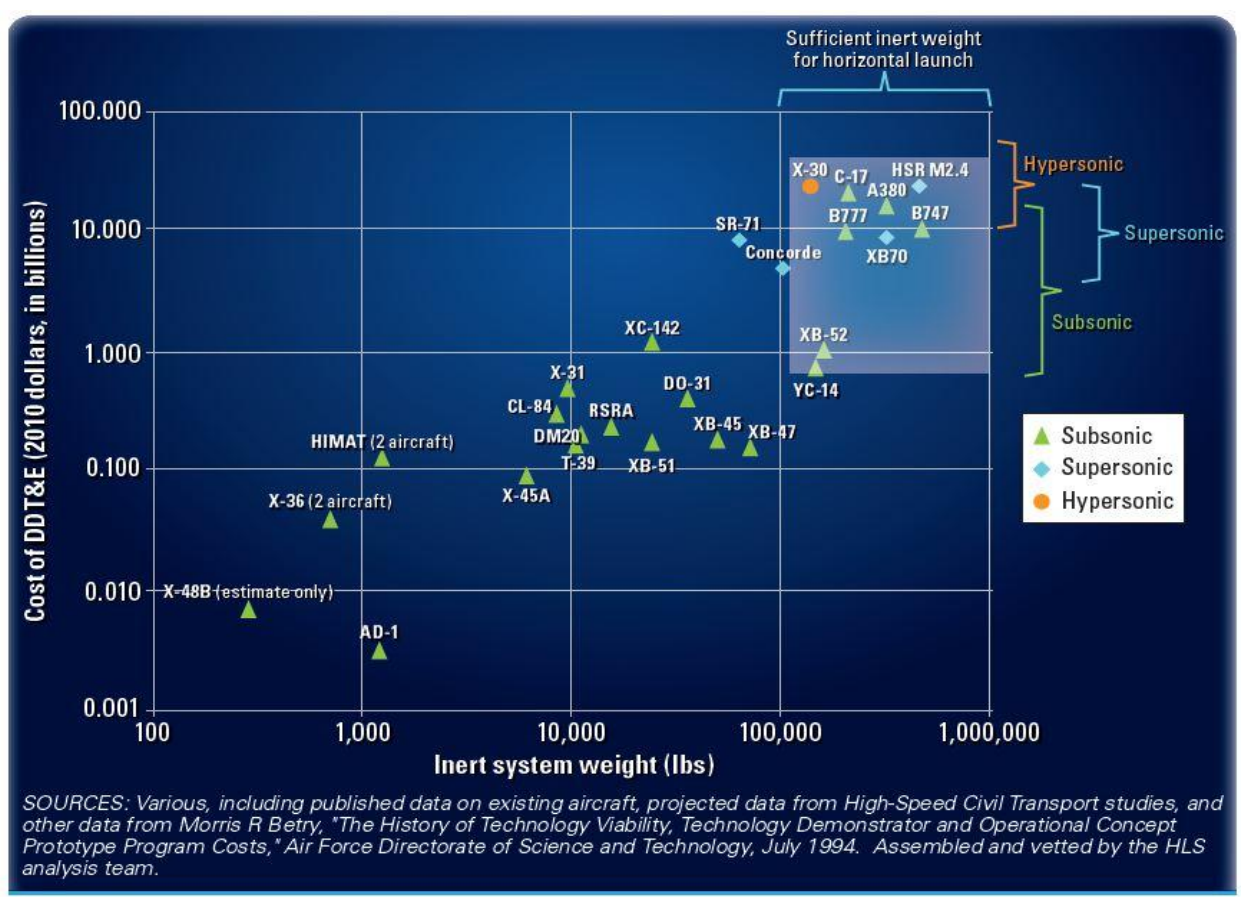
viability. A number of external factors may mitigate this outcome. For example, a government agency could fund the DDT\&E costs of the new system to meet a national imperative for a mobile launch capability. Other scenarios exist that could escalate the flight rate more quickly, thereby reducing the amortized cost significantly. Production may also incorporate adaptive and open manufacturing processes, which can reduce development costs by as much as an order of magnitude.

Figure 3. DDT\&E costs for inert system weight for existing carrier aircraft. (The box is the range of inert system weight sufficient for horizontal launch).

\section{B. Launch Vehicle Configuration}

One of the main decisions driving the design on a horizontal launch system is the placement of the launch vehicle relative to the carrier aircraft. A range of configuration options were considered. The launch vehicle may be carried externally on the top of or on the bottom of the carrier aircraft, stored internally, or towed. All have advantages and disadvantages, as follows:

Internally stowed launch vehicles could have the highest altitude and fastest staging condition for a given carrier aircraft; however, the size of the launch vehicle was limited by the internal payload volume and configuration within the carrier aircraft. The launch vehicle might also need deployable aerodynamic surfaces.

Towed launch vehicles require the fewest modifications to the carrier aircraft and the least constrained separation conditions, but required launch vehicle attachments and wings designed for takeoff, attachments for the dropped takeoff gear, and must be designed for the dynamic loads from the tow line. Towing offered larger payloads than internal stowing and could achieve the goal of 15,000 lb of payload to orbit in some configurations.

Top-mounted launch vehicles on new, large carrier aircraft could carry up to 50,000 lb of payload to $100 \mathrm{~nm}$ due-east orbit. However, launch vehicle separation is a potential concern with respect to getting the carrier aircraft out of the way before rocket ignition.

Bottom-mounted launch vehicles such as the Pegasus rocket on the single-fuselage Lockheed L-1011, Stargazer, were limited by ground clearance that restricts the diameter and length of the launch vehicle. Significant payload performance gains were possible with high-wing, dual-fuselage designs, such as the newly introduced Stratolaunch System $^{2}$ which is a White Knight-derived carrier aircraft having a launch vehicle bottom-mounted on the center wing. This configuration is similar to earlier studied dual-fuselage C-5 and could be tailored to meet almost any payload requirement and enable a wide range of launch trajectories. However, these advantages were 
offset by the need to develop and operate a one-of-a-kind carrier aircraft, and the wingspan and associated takeoff and landing gear that limited basing flexibility.

\section{Carrier Aircraft}

The analysis parameters in the study were selected to enable valid comparisons among the various representative concepts. The outcomes of this comparison served to narrow the focus of the study.

Small supersonic carrier aircraft (e.g., fighters) were found to have very small payload capacity, up to perhaps one hundred pounds. These aircraft had low market potential and high projected costs. Larger existing supersonic aircraft, such as the B-1 Lancer, a variable-sweep wing strategic bomber with supersonic capabilities, were found to have sufficient capability to support a 75,000 lb launch vehicle and could launch payloads up to 5,000 lb. However, the B-1 does not have adequate internal volume for internal carriage of a launch vehicle, nor does it have the needed transonic thrust-minus-drag performance to enable external carriage.

Several new supersonic and hypersonic aircraft were evaluated representing a range of staging Mach numbers and technologies with the potential for larger payloads. Uncertainty in development costs and in operations costs persists across these concepts, driven by varying assumptions in launch rate, reliability, and maintenance requirements. Many of these system concepts could be very competitive if launch rates increased over current market projections of six flights per year.

The remaining aircraft considered were existing subsonic carriers. The most widely available option was the Boeing 747-400F, the cargo version of the commercial airliner that entered into service in 1993. It can be modified to carry an external payload of $308,000 \mathrm{lb}$. A very similar option was the Airbus A380-800F was another commercially available airliner, a wide-body aircraft with an upper deck that extends along the entire length of the fuselage. It can be modified to carry an external payload of $320,000 \mathrm{lb}^{1}$.

Several unique carrier aircraft options were also analyzed. The Antonov An-225 Mriya was a Ukranian-built strategic airlift cargo aircraft designed in the 1980s to ferry the Soviet Buran orbiter. It was the world's heaviest aircraft with a maximum external payload of 440,000 lb. Two Boeing 747 NASA Shuttle Carrier Aircraft, SCA-905 and SCA-911, used for ferrying the Space Shuttle orbiter, were also added to the list of options. These were purpose-modified Boeing 747-100s with a maximum external payload of 192,000 and 240,000 lb, respectively.

Significantly modified carrier aircraft were also considered, such as a dual-fuselage variant of the C-5 Galaxy strategic airlift aircraft with a maximum payload of $771,000 \mathrm{lb}$. Note that a runway wider than 300 feet is required for the breath of the landing gear on the two fuselages which would restrict launch mobility. Two additional derived designs were the White Knight X and White Knight XX (similar to the recently announced Stratolaunch System), enlarged dual-fuselage variants based on the Scaled Composites White Knight Two. The White Knight X was conceived to carry roughly 5 times more payload than the White Knight Two, approximately 176,000 lb. The White Knight XX was conceived as a commercial variant of the dual-fuselage C-5, targeting 750,000 lb payload and using the same development and production methods as the existing White Knight aircraft. The White Knight XX had landing gear wider than 175 feet and would not easily take off from a standard runway.

\section{Common Requirements}

After reviewing the initial screening results, the study stakeholders decided on several requirements for higher fidelity analysis of three point design concepts. The primary requirement was to identify concepts with payloads approaching 15,000 $\mathrm{lbs}$ at the lowest possible DDT\&E cost using current available technologies. As well, production and operations costs should approach those for current launch systems. Finally, to take full advantage of the horizontal launch configuration, the team set a goal to meet conventional runway requirements by limiting the gross takeoff weight of the system to less than 1.8 million lbs.

A critical assumption was that flight rates would follow current market projections for a 15,000 lbs payload class. The team determined that DDT\&E costs would be amortized using a launch rate of six flights per year, each carrying $15,000 \mathrm{lb}$ of payload over a 20 -year system life, for a total campaign of 120 flights. While many previous studies have assumed much higher flight rates attributed to looming national imperatives or order of magnitude increases in launch demand, the study team found no such future demand. Therefore, the rate of six flights per year was assumed throughout the study. 


\section{Screening Results}

\section{A. Results of the Prescreening Analysis}

Historically, horizontal launch concept studies varied greatly in terms of concept of operations, technology, development time, and payload capabilities. However, it became clear from the survey of the past $60+$ years of horizontal launch studies and programs that there were recurring themes between all the horizontal launch system concepts. These concepts can be categorized into 18 distinct representative concepts as shown in Table 2. Based on the literature and analysis, each concept type was categorized into three payload classes (less than $500 \mathrm{lb}, 500$ to $10,000 \mathrm{lb}$, and more than $10,000 \mathrm{lb}$ ) and according to three technology development timeframes: 0 to 3 years (near term), 4 to 9 years (mid term), and more than 10 years (far term).

Table 2. Representative Concepts from the Past 60+ Years of Horizontal Launch Studies/Programs

\begin{tabular}{|c|c|c|c|}
\hline \multirow[b]{2}{*}{$\begin{array}{l}\text { Technology } \\
\text { timeframe }\end{array}$} & \multicolumn{3}{|c|}{ Payload Class } \\
\hline & Less than 500 lbs & 500 to $10,000 \mathrm{lbs}$ & More than 10,000 lbs \\
\hline \multirow{4}{*}{$\begin{array}{l}\text { Near-term } \\
0 \text { to } 3 \text { years }\end{array}$} & Fighter Jet + Multistage & Commercial Jet + Multistage & Ground Sled + Multistage Liquid \\
\hline & Solid Rocket & Solid Rocket & Rocket \\
\hline & & Commercial Jet + Multistage & New Custom Subsonic Carrier + \\
\hline & & & Multistage Liquid Rocket \\
\hline \multirow{7}{*}{$\begin{array}{l}\text { Mid-term } \\
4 \text { to } 9 \text { years }\end{array}$} & Advanced Fighter Jet + & Commercial Jet + Reusable All- & New Subsonic Carrier w/ACES + \\
\hline & $\begin{array}{l}\text { Multistage Liquid } \\
\text { Rocket }\end{array}$ & Rocket Vehicle w/ Drop Tanks & Reusable All-Rocket Vehicle \\
\hline & & & New Supersonic Carrier + \\
\hline & & & Multistage Liquid Rocket \\
\hline & & & Maglev + Reusable RBCC Vehicle \\
\hline & & & $\begin{array}{l}\text { New Supersonic Carrier w/RTA + } \\
\text { Multistage Liquid Rocket }\end{array}$ \\
\hline & & & $\begin{array}{l}\text { New Supersonic Carrier w/Turbo- } \\
\text { Ramjet + Reusable All-Rocket } \\
\text { Vehicle }\end{array}$ \\
\hline \multirow{6}{*}{$\begin{array}{l}\text { Far-term } \\
\text { More than } \\
10 \text { years }\end{array}$} & & Commercial Jet + TBCC Vehicle & TBCC Vehicle + Reusable All- \\
\hline & & + Reusable All-Rocket Vehicle & Rocket Vehicle \\
\hline & & & $\begin{array}{l}\text { RBCC Vehicle + Reusable All- } \\
\text { Rocket Vehicle }\end{array}$ \\
\hline & & & $\begin{array}{l}\text { Hypersonic Vehicle w/LACE and } \\
\text { Scramjet + Expendable Rocket }\end{array}$ \\
\hline & & & $\begin{array}{l}\text { New Supersonic Carrier w/RTA + } \\
\text { Reusable RBCC Vehicle }\end{array}$ \\
\hline & & & $\begin{array}{l}\text { Compressed-Air Rocket Vehicle + } \\
\text { Expendable Rocket }\end{array}$ \\
\hline
\end{tabular}

A number of configuration decisions were made as a result of the prescreening process. A difficult decision was the elimination of supersonic and hypersonic carrier aircraft. A launch vehicle in this speed regime for a moderate payload of 15,000 lb would require an entirely new aircraft, and cost projections for any new aircraft were prohibitive when amortized over 6 flights per year. Therefore, the study focused primarily on existing subsonic aircraft with modifications to accommodate the launch vehicle. 
The next decision was to eliminate towed concepts because they require the development of a winged cradle for launch vehicle takeoff, and internally-loaded concepts because they are volume constrained and cannot accommodate moderate payloads to orbit. Existing bottom-mount concepts were eliminated because the carrier landing gear length constrained the launch vehicle size and system payload. Top separation has been demonstrated with the Space Shuttle orbiter, and bottom-mount separation from a dual-fuselage aircraft may be the easiest to accomplish but limits military basing utility due to existing runway size limitations around the world.

Another decision was to eliminate sled- or rail-based system concepts. Sled-based launch concepts were generally inconsistent with the desire for a completely mobile capability and the ability to use existing runways. For some sled concepts, the sled could double as takeoff and landing gear resulting in weight savings and reduced complexity. However, the sled- and rail-launched systems did not have the ability for launch offset, loiter, or crossrange performance. Based on these results, the following four system concepts were carried forward. These options were selected to span the lowest cost and highest payload opportunities among the near- and mid-term options.

1) Commercial Jet + Multistage Solid Rocket

Carrier aircraft Modified Existing Subsonic Commercial Jet Aircraft

Launch vehicle Expendable Multistage Solid Rocket

2) Commercial Jet + Multistage Liquid Rocket

Carrier aircraft Modified Existing Subsonic Commercial Jet Aircraft

Launch vehicle Expendable Multistage Liquid Rocket (RP fuel)

3) Commercial Jet + Reusable Liquid Rocket with Drop Tanks

Carrier aircraft Modified Existing Subsonic Commercial Jet Aircraft

Launch vehicle Reusable Liquid Rocket (LH2 fuel) with Drop Tanks

4) New Custom Subsonic Carrier + Multistage Liquid Rocket

Carrier aircraft New Specially Designed (Bottom Carry) Large Subsonic Carrier Aircraft

Launch vehicle Expendable Multistage Liquid Rocket

\section{B. Analysis of Carrier Vehicle Alternatives}

The initial results of the analysis of alternatives are shown in Figure 4. Out of the 1,365 combinations, 1,296 feasible solutions were generated. As was observed, the majority of the cases analyzed could carry more payload than the industry price trend line (as determined in Figure 2), but at a higher cost. The maximum payload ranged from 11,180 to 52,290 lb, which varied as the external weight capacity for each carrier aircraft (see Table 3). The lowest life cycle cost / pound of the 1,296 possibilities included either the two- or three-stage solid propellant stage concepts for all of the carrier aircraft. Among the existing carrier aircraft, the highest payload capability results from a configuration with a single stage, drop tank, and LH2 fuel. Twostage LH2 concepts were found to carry less payload than the drop tank concept primarily because the length of the launch vehicle was constrained to fit on top of the carrier aircraft. For the very large An-225, the launch vehicle length constraints were not a limiting factor, resulting in the best twostage LH2 concept.

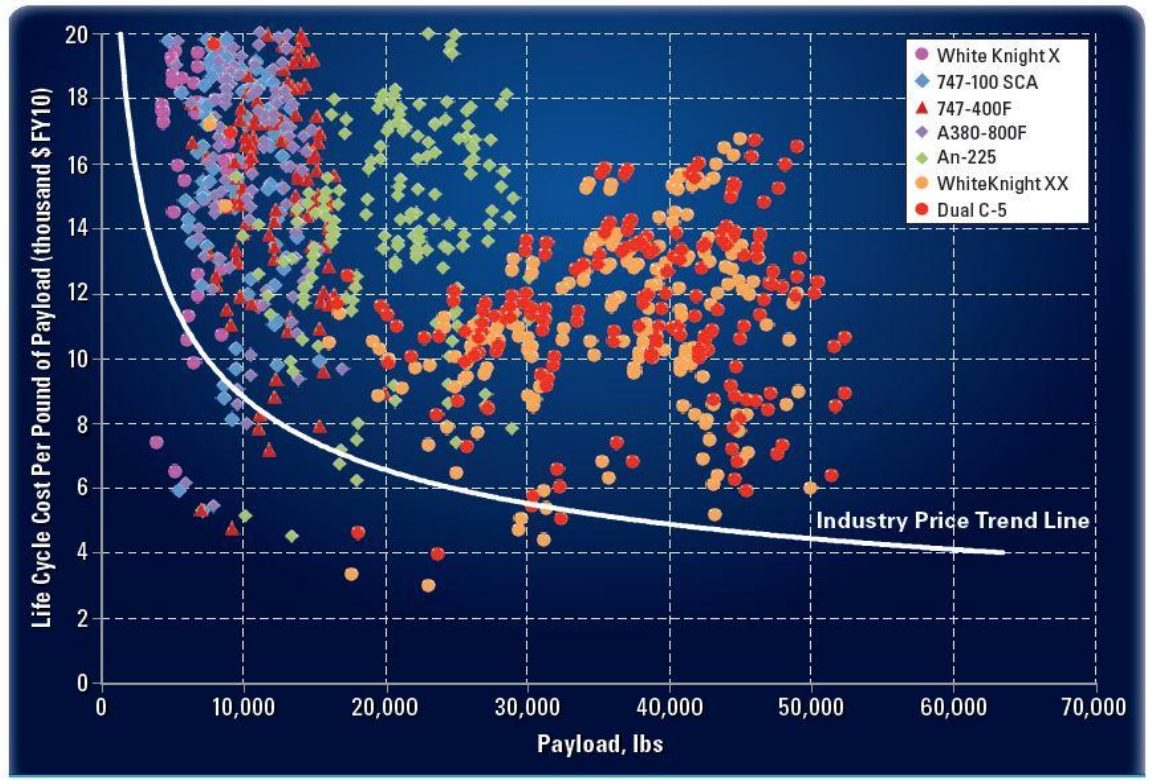

Figure 4. Results of initial analysis of LCC cost and payload capability for 1,296 cases (industry price trend line from figure 2). 
Table 3 System Concept Configurations

\begin{tabular}{lcc}
\hline Carrier Aircraft & External weight capacity (lbs) & Maximum Payload to LEO (lbs) \\
\hline White Knight X & 176,000 & 11,180 \\
747-100 SCA-911 & 240,000 & 15,440 \\
A380-800F & 264,550 & 17,090 \\
747-400F & 308,000 & 20,000 \\
An-225 Mriya & 440,930 & 30,380 \\
White Knight XX & 750,000 & 49,940 \\
Dual-fuselage C-5 & 771,620 & 52,290 \\
\hline
\end{tabular}

DDT\&E cost values for the 747-100 SCA, 747-400F, and A380-800F were relatively low, owing to the assumption that existing aircraft would be used. The three dual-fuselage aircraft were all treated as new acquisitions. The dual-fuselage C-5 development costs were based on the assumption that modifications would be extensive on an airplane of this vintage. On the other hand, optimistic development assumptions were made for the White Knight configurations based on the aggressive development history at Scaled Composites. The DDT\&E costs for the White Knight XX were lower than for the dual-fuselage C-5, in spite of the fact that the C-5 is an existing production aircraft.

The White Knight $X$ had the lowest payload capability and the highest recurring costs per pound of payload, leading to the observation that a concept sized between the White Knight X and XX may have struck a better balance between mobility and payload. The dual-fuselage C- 5 had the largest external payload capability and the highest delivered payload in a two-stage LH2 configuration.

The FOMs other than payload and cost did not provide many discriminators. The solid propellant stage concepts were assumed to have less restrictive handling and propellant storage requirements as compared to liquid engines. Although much lower in cost and with less propellant infrastructure than liquid stage concepts, they had the lowest payload capability - approximately half that of the LH2 concepts owing to the differences in specific impulse. Finally, the probability of loss of mission for all cases ranged from 1.9 to 3.5 percent. In this low-fidelity screening analysis, this variation was considered insignificant.

While all the carrier aircraft analyzed could arguably meet the goals established in the study, each had their own strengths and weaknesses in the FOMs analysis. The White Knight X had the lowest payload capability compared to other existing commercial aircraft, with no compensating advantages. The White Knight XX and dual-fuselage C-5 both displayed large uncertainties in performance. The capability of A380-800F aircraft essentially duplicated the 747 capabilities, and it was found to be more expensive to acquire. Finally, only one An-225 Mriya aircraft exists currently and the team considered the risks of purchasing and maintaining such a unique specimen as being very high.

Based on these results, only the 747-400F was carried forward as a carrier aircraft for further analysis. The 747$400 \mathrm{~F}$ is widely available as a used aircraft and is well characterized in many discipline models. For these reasons, it was judged by the study team as having the greatest potential to demonstrate overall horizontal launch feasibility.

\section{Analysis of Launch Vehicle Alternatives}

Various launch vehicle configurations also had different strengths and weaknesses. The system concepts with two- and three-stage solid rockets generally had the lowest costs and the lowest payload capability. At the other end of the spectrum, the three-stage LH2 system concept had the highest LCCs, but not always the highest payload. The one-stage LH2 concept with drop tank generally had the best payload capability. The low-density and high-volume of the two-stage LH2 systems required a very low fineness ratio, and the multiple stages and engine nozzle lengths required long interstage adapters. For example, the two-stage and three-stage LH2 concepts had less payload than the drop tank concept on the 747-400F because the launch vehicle length was constrained to $127 \mathrm{ft}$.

The results reveal the potential to meet the study goals with the $747-400 \mathrm{~F}$ carrier aircraft. The payload capability estimates for a 747-400F ranged from 7,150 lb with solid rockets to 20,000 lb with liquid engines. Of specific interest is two-stage RP launch vehicle, which delivered more than 10,000 lb of payload in this configuration while avoiding the operational complexities of storage and handling of liquid hydrogen. 


\section{Results of the Screening Analysis}

This analysis of horizontal launch concepts showed their competitiveness as compared to the industry price trend line in Figure 2. It is difficult, however, to project better performance than the advertised price of modern vertical launch systems such as the Falcon 9 two-stage RP system or the Taurus II RP+solid (plus optional hypergolic third stage). While the cost of the two- and three-stage solids could be in range considering the conservative assumptions of this model, the costs of the liquid rocket system concepts were substantially larger. Thus three configurations were selected for higher fidelity analysis. Based on the screening results, a low cost solid concept, a high payload two-stage LH2 concept, and a compromise RP+LH2 vehicle were chosen. The drop tank concept, while promising, did not have a detailed model available to fully compare this configuration. Further consideration of this potentially competitive concept should be addressed in future studies.

\section{Point Designs}

The three selected concepts that emerged from the screening exercise were further refined to determine development feasibility and risk at a higher level of fidelity. These concepts were developed into point design system concepts (PDs), intended to represent the expected range of performance, reliability, cost, and risk for a class of horizontal launch concepts. Figures 5-8 present conceptual views of these three designs.

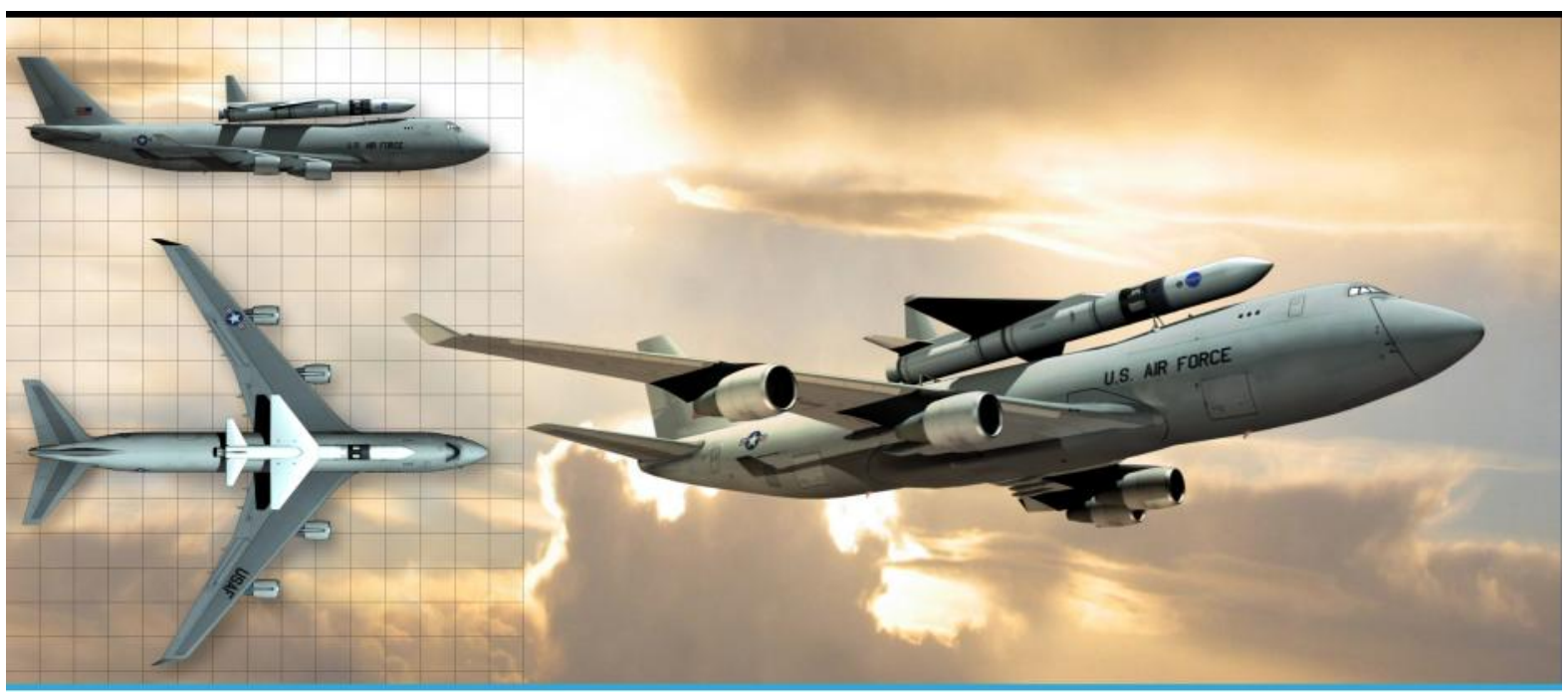

Figure 5. PD-1 horizontal launch concept utilizing 747-400F carrier aircraft \& a 3-stage solid launch vehicle.

The analyses optimized the various design parameters in order to maximize the payload delivered to orbit, and determined the best existing rocket motor or engine and other critical subsystems to reduce the development risk and uncertainty of system weight and cost predictions.

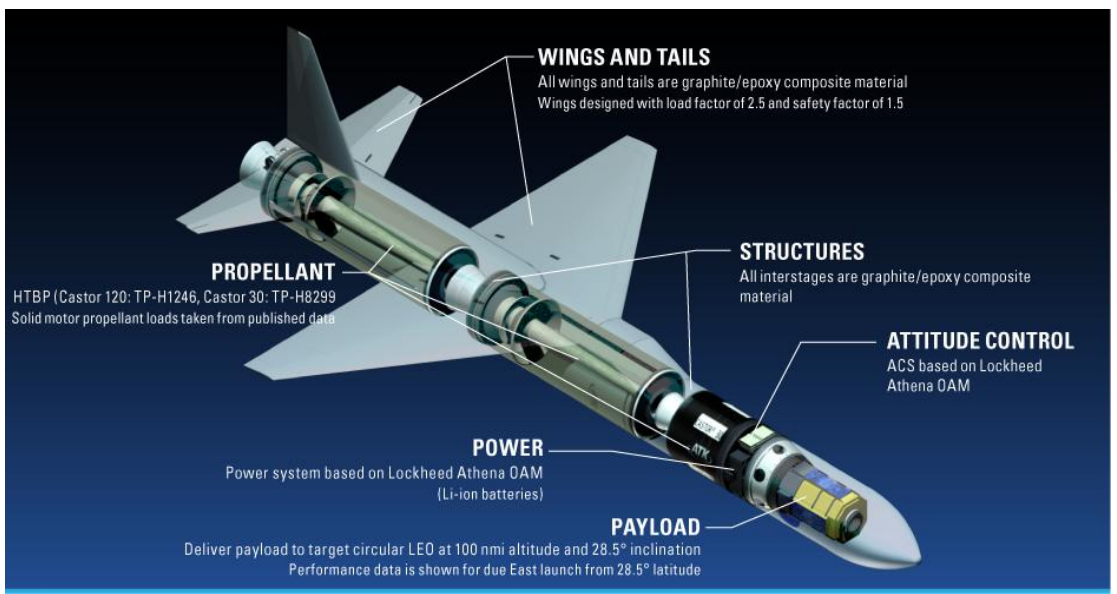

Major aspects of the point design methodology include the following:

- The launch vehicle gross weight was sized to meet the maximum carrying capacity of the carrier aircraft.

- The performance and costs were calculated based on the properties of existing engines rather than scaling nonexistent engines.

- Technical discipline tools (e.g., trajectory, aerodynamics,

propulsion, mass properties), rather than response surfaces, were used.

Figure 6. PD-1 launch vehicle concept utilizing 3-stage solid booster.

10

American Institute of Aeronautics and Astronautics 
- The NAFCOM cost model was used because it computes DDT\&E and theoretical first unit cost at the subsystem level.

The goals for the vehicle concept exploration were to identify concepts with useful payloads approaching 15,000 lbs for a $28.5^{\circ}$ due east, 100-nautical mile orbit with low development costs and with production and operations costs approaching those of current launch systems. To ensure military and commercial usefulness, the concepts were constrained to existing runways with a gross takeoff weight less than 1.8 million $\mathrm{lb}$.

Flight rates were set at current market projections of 6 flights per year. This nominal 60 days between flights was used to size the operations crew needed for the campaign. The ground crew size was also used to determine surge call-up time and minimum turnaround time.

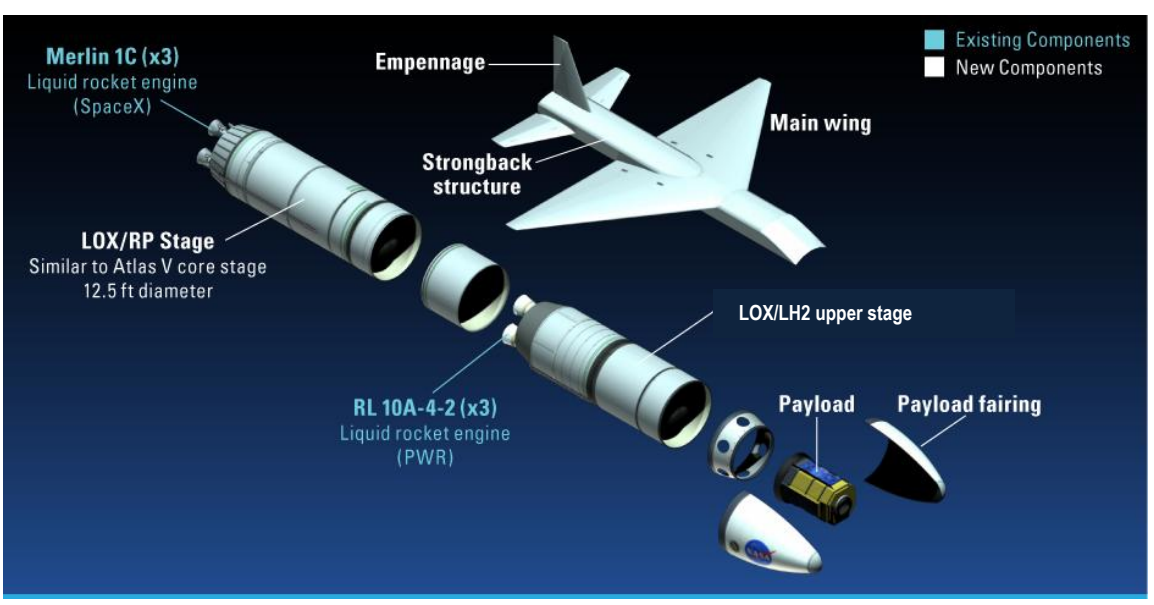

Figure 7. Expanded view of PD-2 launch vehicle utilizing liquid boosters.

To select the best existing engines and other subsystems while optimizing the payload of the system, an array of analysis tools were integrated into a framework to link control variables.

A parametric geometry model scaled the wing geometry based on wing loading constraints, stage length and diameter based on propellant requirements and carrier aircraft constraints. Aerodynamics, rocket performance, and system weight were communicated to the Program to Optimize Simulated Trajectories (POST) program to maximize payload. If the launch vehicle did not meet all the constraints, the vehicle geometry (diameter and length), aerodynamic surfaces, and thrust were resized until the payload was optimized and all constraints were met. The results of the aerodynamic analyses for the point designs, along with configuration details and trajectory analyses, are included in Reference 1.

\section{A. Point Design Definitions}

As modified, the 747-400F (see Figure 5) was assumed to have a total length of 231 feet, a wingspan of 211 feet, and a design payload capacity of 305,000 lb. Details of the three configurations analyzed are presented in Table 4. The PD-1 (Figure 6) was selected to represent the lowest DDT\&E costs, and PD-3 (Figure 8) was selected to represent the highest payload. The PD2 (Figure 7) configuration was selected as a compromise between performance and cost. Because the launch vehicles were modeled from existing solid rocket motors, the PD-1 payload capacity is significantly less than the design goal.

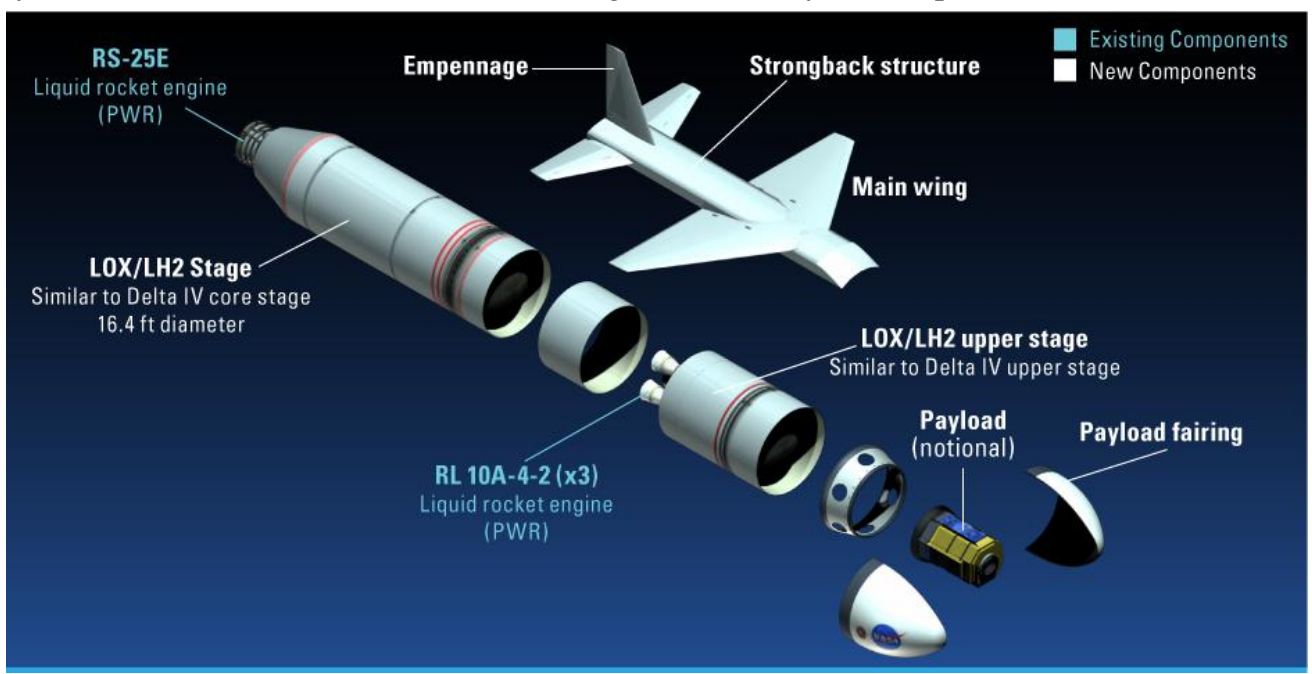

Figure 8. Expanded view of PD-3 utilizing liquid boosters to maximize payloads. 


\section{B. Weight Breakdown Comparisons}

A detailed weight breakdown for each point design system concept can be found in Reference 1 . In all cases, the integrated aerodynamic surface module was jettisoned early in the trajectory modeling and thus its weight has only a few hundred pounds of impact on the payload delivery capability. For PD-1, the selection of the three existing solid rocket motors meant the optimized gross weight of the launch vehicle was less than the maximum the $747-400 \mathrm{~F}$ could carry. This allowed a reduction in the internal structural modifications and lowered the development costs of the 747. The payload delivered by PD-1 was computed to be 5,660 lb. For PD-2, payload delivery was computed to be $12,580 \mathrm{lb}$ for the closed vehicle, and PD-3, payload delivery was computed to be $17,810 \mathrm{lb}$.

Table 4. Configuration Descriptions of the Point Design Horizontal Launch Systems Including Costs

\begin{tabular}{lrrr}
\hline & PD- 1 & PD- 2 & PD- 3 \\
\hline Carrier Aircraft & $747-400 \mathrm{~F}$ & $747-400 \mathrm{~F}$ & $747-400 \mathrm{~F}$ \\
Launch Vehicle & 3-stage solid & 2-stage RP/LH2 & 2-stage LH2/LH2 \\
Payload to LEO & $5,660 \mathrm{lbs}$ & $12,580 \mathrm{lbs}$ & $17,810 \mathrm{lbs}$ \\
Launch Vehicle Gross Weight & $288,480 \mathrm{lbs}$ & $305,000 \mathrm{lbs}$ & $305,000 \mathrm{lbs}$ \\
Launch Vehicle Length & $100 \mathrm{ft}$ & $102 \mathrm{ft}$ & $114 \mathrm{ft}$ \\
Launch Vehicle Maximum Diameter & $7.8 \mathrm{ft}$ & $12.5 \mathrm{ft}$ & $16.4 \mathrm{ft}$ \\
Launch Vehicle Wing Span & $57 \mathrm{ft}$ & $62 \mathrm{ft}$ & $53 \mathrm{ft}$ \\
DDT\&E and facilities costs & $\$ 475 \mathrm{M}$ & $\$ 940 \mathrm{M}$ & $\$ 2,440 \mathrm{M}$ \\
Recurring costs/payload & $\$ 8,930 / \mathrm{lb}$ & $\$ 9,560 / \mathrm{lb}$ & $\$ 7,300 / \mathrm{lb}$ \\
Recurring costs/flight & $\$ 51 \mathrm{M} / \mathrm{flight}$ & $\$ 120 \mathrm{M} / \mathrm{flight}$ & $\$ 130 \mathrm{M} / \mathrm{flight}$ \\
\hline
\end{tabular}

\section{Reliability Comparisons}

Using failure rates of existing systems and the reliability exponential growth history of past systems, the loss of mission probabilities are shown in Table 5. Analysis of the most important elements revealed no dominating unreliable components.

Table 5. Reliability Assessment for Point Design System Concepts

\begin{tabular}{lllrrrrr}
\hline & \multicolumn{2}{c}{ PD 1 } & \multicolumn{2}{c}{ PD 2 } & \multicolumn{2}{c}{ PD 3 } \\
\hline \multirow{4}{*}{ 4th Flight } & \multicolumn{3}{c}{ Probability of loss of mission (Mean flights before failure) } \\
& Loss of 747-400F & $0.006 \%$ & $(17,241)$ & $0.006 \%$ & $(17,241)$ & $0.006 \%$ & $(17,241)$ \\
& Failed separation & $1.0 \%$ & $(101)$ & $1.0 \%$ & $(101)$ & $1.0 \%$ & $(101)$ \\
& Loss of Stage 1 & $2.07 \%$ & $(48)$ & $1.72 \%$ & $(58)$ & $1.95 \%$ & $(50)$ \\
& Loss of Stage 2 & $1.35 \%$ & $(74)$ & $2.37 \%$ & $(42)$ & $2.36 \%$ & $(41)$ \\
& & & & & & & \\
167 16th Flight & Loss of 747-400F & $0.001 \%$ & $(71,428)$ & $0.001 \%$ & $(71,428)$ & $0.001 \%$ & $(71,428)$ \\
& Failed separation & $0.24 \%$ & $(419)$ & $0.24 \%$ & $(419)$ & $0.24 \%$ & $(419)$ \\
& Loss of Stage 1 & $0.50 \%$ & $(199)$ & $0.41 \%$ & $(254)$ & $0.47 \%$ & $(212)$ \\
& Loss of Stage 2 & $0.32 \%$ & $(300)$ & $0.57 \%$ & $(175)$ & $0.56 \%$ & $(178)$ \\
\hline
\end{tabular}

\section{Costs Comparisons}

Program costs, listed in Table 4, were estimated using a number of assumptions. Chief among these was the acquisition and modification of a used 747-400F for $\$ 86$ million, and the subsequent DDT\&E of $\$ 122$ million for this aircraft. These estimates were based on past Boeing AirLaunch studies ${ }^{1}$, using current year dollars. DDT\&E costs of the strongback aerosurface modification were based on traditional aerospace practices employing the NAFCOM model. 
In addition, the typical government oversight for the program was based on previous manned system development, and government facilities (and their associated costs) were used for testing and demonstration.

- For PD-1, market price was used for the solid rocket stages. The recurring costs per flight were calculated to be $\$ 51$ million, or $\$ 8,930$ per pound of payload.

- For PD-2, the Merlin 1C costs were calculated in NAFCOM based on the advertised price of the SpaceX Falcon 1 and Falcon 9. The recurring costs per flight were estimated at $\$ 120$ million, or $\$ 9,560$ per pound of payload.

- For PD-3, the RS-25E costs were estimated using NAFCOM. Note that the RS-25E technology development costs (primarily for air-start capability) have not been added to DDT\&E estimates. The recurring costs per flight were $\$ 130$ million, or $\$ 7,300$ per pound of payload.

\section{E. Summary of Point Design System Concepts}

The results of the analysis show that even within the constraint of using existing engines, the resulting systems still produced good payload performance, cost, and reliability. The three-stage solid, PD-1, had the lowest DDT\&E costs. The two-stage LH2 PD-3 had the highest payload delivery and the lowest LCC per pound of payload. A detailed summary for each Point Design concept including figures of merits can be found in Reference 1.

\section{Flight Test System Concepts}

In the previous section three horizontal launch vehicle concepts have been presented as realistic options to launch a nominal $15,000 \mathrm{lb}$ payload to LEO utilizing a 747-400F with a winged launch vehicle carried on top. While the use of existing technologies for the major system elements has greatly reduced the uncertainties in each concept, flight tests will be required to reduce three major technical uncertainties; namely, (1) separation physical mechanism and aerodynamics, (2) in-flight command and control of the launch vehicle, and (3) cryogenic handling and storage.

To mitigate these risks for a development program, two flight test system concepts (FTs) were developed to define design requirements and program costs. The results of this exercise serve to quantify the next steps required for the development of a national horizontal launch capability.

\section{A. Flight Test System Concept Configurations}

The flight test concepts (Table 6) were derived by modifying existing expendable, vertical launch vehicles to produce horizontal launch vehicles. Two existing launch vehicles were used as baselines and modified for horizontal launch. The carrier aircraft for both was the 747-100 SCA-905. As modified, this aircraft was assumed to have a total length of $231 \mathrm{ft}$, a wingspan of $196 \mathrm{ft}$, and a design payload capacity of $192,000 \mathrm{lb}$. Conceptual views of these two FTs are shown in Figures $9-11$.

The analysis for these concepts followed the same methods as used for the point design concepts to determine weight, development costs, and reliability. Flight test costs were based on current production costs, operations costs, and an estimate of government and contractor flight test support requirements based on past programs.

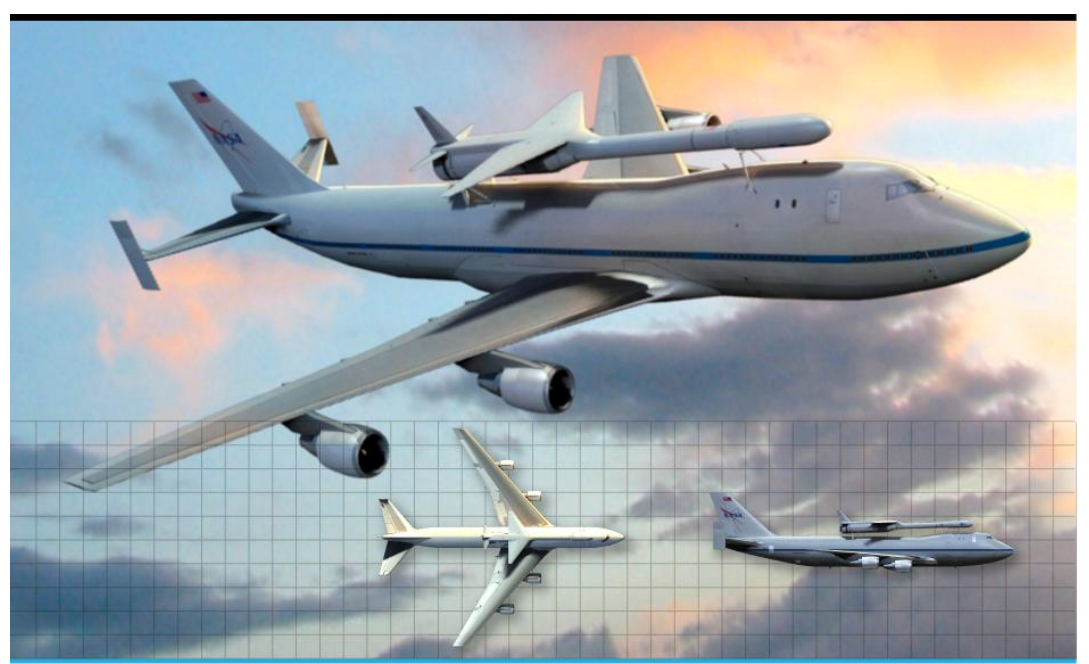

Figure 9. FT-1 test vehicle concept utilizing a modified Taurus XL launch vehicle with NASA's Shuttle Carrier Aircraft. 
Table 6. Summary of Flight Test System Concepts

\begin{tabular}{lll}
\hline & FT-1 & FT-2 \\
\hline Launch vehicle & modified Taurus XL & modified Falcon 1e \\
Total gross weight & $179,470 \mathrm{lb}$ & $81,990 \mathrm{lb}$ \\
Payload to LEO & $4,560 \mathrm{lb}$ & $2,750 \mathrm{lb}$ \\
Total length & $99 \mathrm{ft}$ & $81 \mathrm{ft}$ \\
Maximum fuselage diameter & $7.8 \mathrm{ft}$ & $5.5 \mathrm{ft}$ \\
Wing span & $47 \mathrm{ft}$ & $26 \mathrm{ft}$ \\
\hline
\end{tabular}

\section{B. Trajectory and Separation Analyses}

Using the motor/engine thrust profiles and launch vehicle aerodynamics, the resulting trajectories were calculated using POST. Once the launch vehicle attained a typical vertical flight profile, the aerodynamic surfaces were jettisoned. Further details of the configuration, aerodynamics, and trajectory analysis for both FT-1 and FT-2 can be found in Reference 1.

For FT-1, the launch vehicle reaches a maximum dynamic pressure of 2,248 psf which was very aggressive compared with a nominal launch vehicle maximum dynamic pressure of approximately $800 \mathrm{psf}$. However, there are vehicles that can survive a large dynamic pressure, for instance the successful X-43A airframe-integrated scramjet vehicle was designed to an upper limit greater than 2,000 psf during its ascent to the test point on a modified Pegasus booster ${ }^{3}$. The payload performance versus constrained maximum dynamic pressure was not studied in this analysis, but the possibility exists that this state could negatively impact the payload capability perhaps by requiring a stiffer outer structure. The nonconstrained trajectory payload delivery was computed to be $4,560 \mathrm{lb}$.

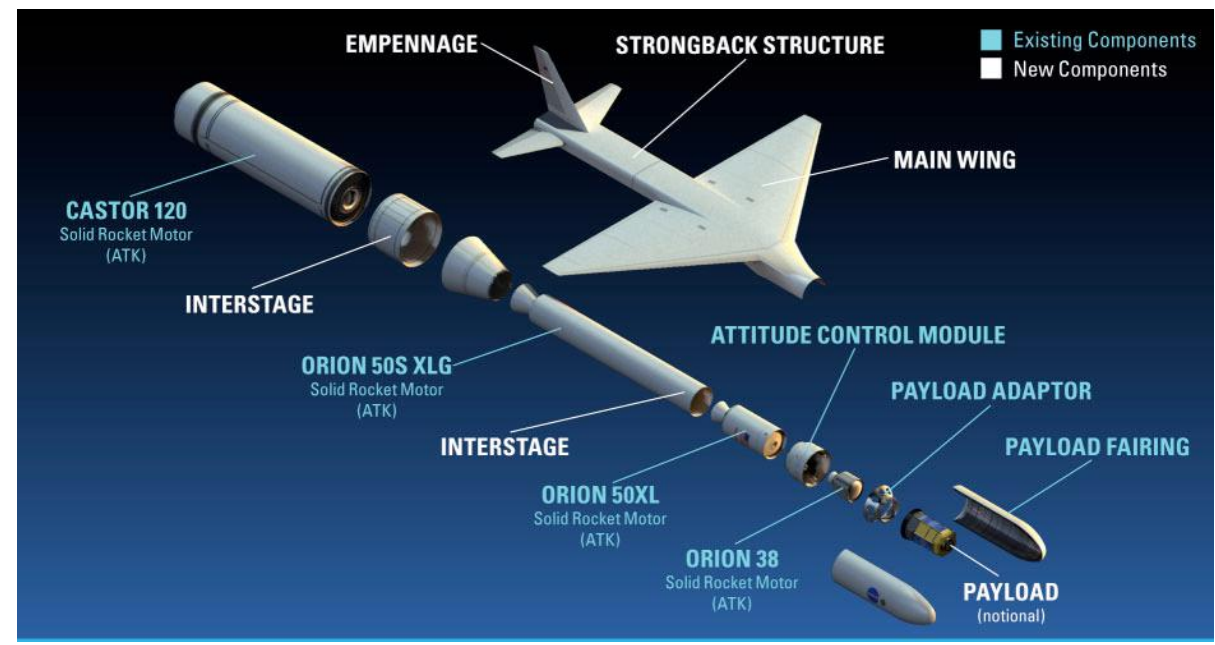

Figure 10. The launch vehicle concept for FT-1 utilizing a modified Taurus XL.

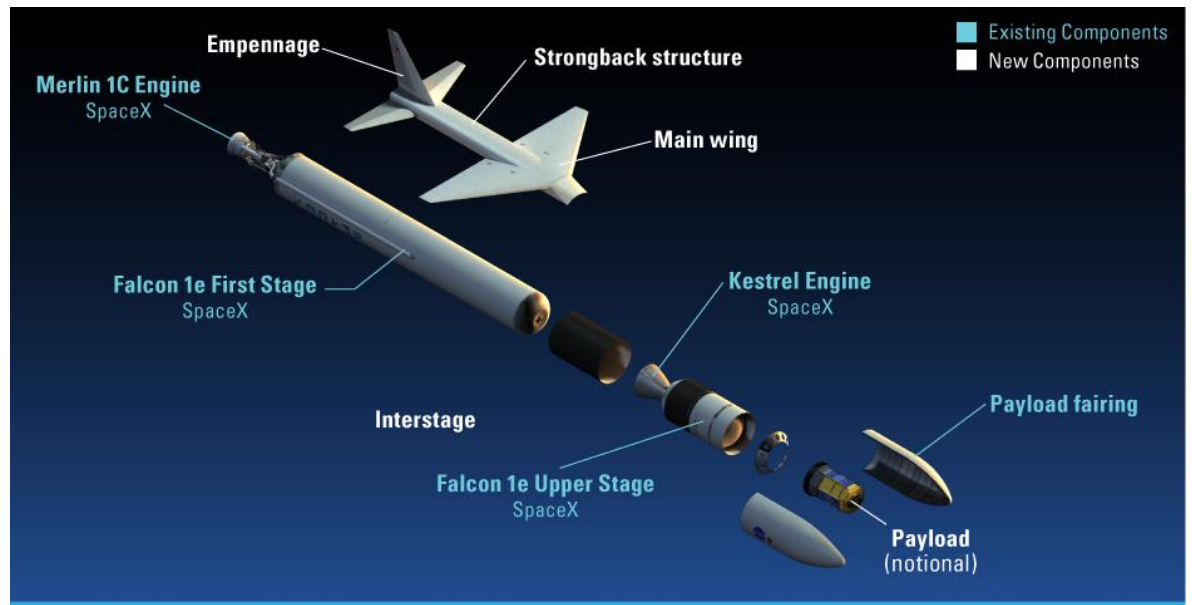

For FT-2, the launch vehicle reaches a maximum dynamic pressure of 980 psf. The non-constrained trajectory payload delivery was computed to be $2,750 \mathrm{lb}$.

Preliminary separation analysis indicates that these separation scenarios were adequate, but further detailed analysis must be conducted for verification.

Figure 11. The launch vehicle concept for FT-2 utilizing a modified Falcon 1e.

14

American Institute of Aeronautics and Astronautics 


\section{Reliability Comparisons}

Using failure rates of existing systems, the success probabilities for the first flight of FT-1 and FT-2 were estimated at $78 \%$ and $83 \%$, respectively. For FT-1, the fairing separation has been determined to be the largest contributor, based on two recent consecutive Taurus payload fairing failures. The fairing separation was an order of magnitude higher than all other propulsion and human error events. The predicted reliability improves with each flight based on historical reliability growth curves for past systems with an average increase of probability of $2 \%$ with each subsequent flight. Because these issues were expected to be resolved for the Taurus rocket for future missions, the reliability predictions may be considered very conservative. For FT-2, the Falcon 1e has had similar flight test performance as previous liquid rocket systems. The probability of success was therefore somewhat higher than the modified four-stage solid FT-1 concept.

\section{Cost Analyses}

Program costs were estimated assuming that the 747 SCA-905 would be available at the current funding levels for two demonstration flights over 3.5 years. Component costs were calculated using NAFCOM which was anchored to the prices for components and systems advertised by the manufacturers-e.g., Orbital Sciences and SpaceX. The cost of government oversight/insight into the program and government facilities (with their associated costs) for testing and demonstration were determined through expert elicitation. The estimated program cost for FT1 is $\$ 320 \mathrm{M}$, while the estimated program cost for FT-2 is $\$ 245 \mathrm{M}$, in 2011 dollars. The difference in program costs reflects differences in costs between the Taurus XL and Falcon 1e.

\section{E. Summary of Flight Test System Concepts}

The four-stage solid FT-1 has an estimated higher payload but also higher development costs compared to FT-2. Based on the assumption that the two-stage liquid FT-2 can be developed at the same cost as the SpaceX Falcon family of launch vehicles, total cost favors the two-stage liquid FT-2. The failure risk for the solid FT-1 was higher but was based on the recent history of payload fairing separation failures of the Taurus launch vehicle. If these problems were solved and typical failure rates prevail, the risks were similar for the two configurations.

The FT-2 two-stage liquid has a number of advantages for a demonstration. This option would demonstrate all the necessary operational needs including LOX logistics, storage on ground, and storage in flight. In addition, it was anticipated that the configuration would allow the payload to be increased by lengthening the stages (within the limits determined by a structural bending loads analysis and carrier aircraft constraints).

\section{Conclusions}

The vision of horizontal launch is the capability to provide a "mobile launch pad" that can use existing aircraft runways, cruise above weather, loiter for mission instructions, and provide precise placement for orbital intercept, rendezvous, or reconnaissance. This study identifies a viable near term path forward to make the vision of a robust and resilient horizontal launch capability a reality.

A number of assumptions and constraints were used to guide the study process. These included due east launch at 28.5 degrees, limits of existing runways, current and projected launch rates in various payload classes, and the performance parameters of existing technologies and existing designs.

For a more modest investment, a modified existing subsonic carrier aircraft with a liquid propellant launch vehicle could carry an estimated payload up to $20,000 \mathrm{lb}$ with LCCs of $\$ 8,860$ per pound. The DDT\&E cost for this system, including modifying an existing carrier aircraft and assembling a conventional LH2-fueled launch vehicle, was estimated at less than $\$ 2$ billion. This initial analysis established the potential to launch militarily-relevant payloads to low-Earth orbit with current, commercially-available carrier aircraft and available launch vehicle technology.

With a focus on achieving the reference payload of $15,000 \mathrm{lb}$ to orbit, three reference point design system concepts were developed. One near-term system was a two-stage launch vehicle with an RP-fueled first stage and an LH2-fueled second stage, both carried to a launch point altitude of $25,000 \mathrm{ft}$ by a modified Boeing $747-400 \mathrm{~F}$ carrier aircraft. The nonrecurring costs for this point design system concept were estimated at $\$ 940$ million, and a recurring cost of approximately $\$ 9,600$ per pound of payload to orbit. Aerial fueling of the carrier aircraft could provide further performance and cost benefits by allowing a larger launch vehicle and payload weight while meeting the 
carrier aircraft's maximum take-off weight. Utilization of existing technologies was found to be sufficient to immediately begin design of a subsonic carrier aircraft-based space launch system.

Flight technology demonstration concepts were also defined using existing propulsion subsystems and technologies. This system concept consisted of the NASA Shuttle Carrier Aircraft (a modified Boeing 747-100) with either a solid or liquid propellant launch vehicle mounted on top. It was estimated that this demonstration program would cost less than $\$ 350$ million over three to four years and would achieve two demonstration flights with up to $5,000 \mathrm{lb}$ of payload to low Earth orbit. The flight demonstration would generate experience and understanding to reduce and mitigate risks to horizontal launches. Most important among these are the ability for in-flight command and control of the launch vehicle and the aerodynamic parameters for separation of the carrier aircraft and launch vehicle.

The design reference mission (DRM) used in this study was overly generic in order to show that a subsonic carrier aircraft can be economically developed and utilized to deliver a 15,000 lb payload. But without a true DRM, it was impossible to state that this was "the best" launch option. Suitability depends entirely on the mission, and missions were each unique to the end user. One size will never fit all.

Launch system performance such as payload volume and weight, orbital inclination and altitude, and other factors were also highly dependent on the mission. All these factors affected recurring costs and LCCs. Completing the cycle, higher annual launch rates or the ability to combine multiple payloads into a single launch was a direct function of payload capability; both had the potential to significantly reduce recurring costs. Development of a horizontal launch system will require specific DRMs to define design requirements. While the results from this study can be used as guidance for these future developments, it does not represent a definitive solution.

To define a DRM for a future horizontal launch vehicle system, several tradeoffs must be mutually understood by the designer and stakeholder early in the design cycle. The most important trades have to do with the characteristics of the payload. These include total volume, total mass, center of gravity, mass distribution, and maximum diameter and length. Payload characteristics directly affect recurring costs by allowing a wider range of launch market opportunities for different payload types, thereby increasing launch rates and decreasing costs. No other design factor (i.e., component reusability, advanced technologies, efficient operations, etc.) has a greater significance in lowering LCC than flight rate.

This study used estimated launch system costs as a figure of merit. Recurring costs, DDT\&E costs, and LCC were all considered. The assumptions that go into a LCC analysis include projected annual flight rates, program duration, estimated decreased production costs over time, anticipated maintenance schedules for reusable systems, and increased operational efficiencies over time. Using only LCC without considering the cost breakdown can be misleading if highly optimistic launch rates were used. This was the case for the NASA Shuttle program, where a 440-launch design life was projected with a minimum of 28 launches per year (and as high as 55 launches per year). During its best year in 1985, the Shuttle launched 9 times and the program totaled just 135 launches overall. The realities of flight rate for the Space Shuttle ranged from a high of 9 to a low of zero launches per year. Amortizing the $\$ 5.1$ billion (1970 dollars) over 440 launches resulted in DDT\&E costs of a seemingly-affordable $\$ 12$ million per launch. In reality, the Shuttle's DDT\&E costs consumed over 50 percent of NASA's annual budget for six years. For these reasons, a conservative and realistic launch rate was assumed in this study.

Concerns about DDT\&E costs drove the selection of a subsonic carrier aircraft over supersonic and hypersonic carrier concepts. An existing subsonic carrier vehicle, the 747-400F, was also selected over a new subsonic carrier. With total DDT\&E costs of less than $\$ 2$ billion for the entire system, the 747-400F provided the payload capability at a fraction of the DDT\&E costs of a new subsonic carrier alone.

No existing supersonic or hypersonic vehicle can carry a launch vehicle capable of delivering a 15,000 lbs payload to LEO. While these would have the potential for larger payloads and lower operations costs over the subsonic concepts, the DDT\&E costs estimated in this study $-\$ 17$ billion to develop a new supersonic carrier and $\$ 25$ billion to develop a new hypersonic carrier-would challenge any budget justification. Because the common requirements used in this study did not have a DRM that required a high speed carrier aircraft, the wide variation in DDT\&E costs made this a decisive discriminator among carrier aircraft options. 


\section{Acknowledgments}

The authors acknowledge the hard work and efforts of the engineers and analysts of Analytical Mechanics Associates, McKinney Associates, SpaceWorks Enterprises, Inc. and Strategic Analysis Inc. who provided their technical expertise and input into the DARPA/ NASA Horizontal Launch Study.

\section{References}

${ }^{1}$ Bartolotta, P.A., Buchen, E., Engelund, W.C., Huebner, L.D., Moses, P.L., Schaffer, M.G., Voland, R.T., Voracek, D.F., and Wilhite, A.W., "Horizontal launch: a versatile concept for assured space access," NASA SP 2011-215994.

${ }^{2}$ Belfiore, M., "Mega Jet," Popular Mechanics, April 2012.

${ }^{3}$ Joyce, P., M. Pudoka, V. Allen, and J. Pomroy, "Flight Test Design Considerations for Rocket-Boosted Hypersonic Flight Research", JANNAF 35th Combustion Subcommittee/Propulsion Systems Hazards Subcommittee/and Airbreathing Propulsion Subcommittee Joint Meetings, December 1998. 